\title{
Preventing Hepatocellular Carcinoma: The Case for Childhood Intervention
}

\author{
Sania $\mathrm{Amr}^{1,2}$ and Christopher A. Loffredo ${ }^{3}$ \\ 'Department of Epidemiology and Public Health, University of Maryland School of Medicine \\ ${ }^{2}$ Marlene and Stuart Greenebaum Comprehensive Cancer Center, University of Maryland School of Medicine, Baltimore, Maryland \\ ${ }^{3}$ Lombardi Comprehensive Cancer Center, Georgetown University, Washington DC
}

Article Info

\section{Article Notes}

Received: September 29, 2018

Accepted: November 19, 2018

\section{${ }^{*}$ Correspondence:}

Dr. Sania Amr, MD, MS, Facpm, Department of

Epidemiology and Public Health, University of Maryland

School of Medicine, 660 West Redwood Street HH 109,

Baltimore MD 21201, USA; ORCID \#:0000-0002-1193-877X;

Email: samr@som.umaryland.edu.

(c) $2018 \mathrm{Amr} \mathrm{S}$. This article is distributed under the terms of the Creative Commons Attribution 4.0 International License.

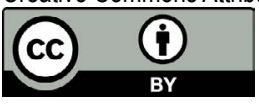

\section{Keywords:}

Hepatocellular carcinoma (HCC)

Hepatitis B (HBV)

Hepatitis C (HCV)

Aflatoxin

Alcoholic cirrhosis

Non-alcoholic fatty liver disease (NAFLD)

pesticides

Prevention

Children

\section{ABSTRACT}

Hepatocellular carcinoma (HCC) is on the rise worldwide and in the US, and despite emerging treatment modalities, its overall prognosis remains poor; therefore, there is a need for preventing its development globally. The major factors contributing to $\mathrm{HCC}$ development, namely, infections with hepatitis B and hepatitis $C$ viruses, alcoholic cirrhosis, aflatoxin-contaminated food, nonalcoholic fatty liver disease, metabolic syndrome, and smoking are modifiable; and prevention intervention can start in childhood.

Vaccination for hepatitis $B$, screening for and treatment of hepatitis $C$ and intravenous drug users, education to avoid fatty liver, alcoholism, and substance use were shown to be effective ways to curb HCC incidence. A focus on reducing early childhood adversity and training young children to make healthy decisions has been strongly recommended as a prevention strategy to reduce most of HCC risk factors.

\section{Introduction}

Hepatocellular carcinoma (HCC) is on the rise worldwide ${ }^{1}$ and in the US ${ }^{2,3}$. It disproportionally affects areas endemic for hepatitis C (HCV) and hepatitis B (HBV) viruses, such as Egypt and southeast Asia, respectively $y^{4,5}$. Therapeutic options depend on the cancer stage $e^{6,7}$, which is commonly advanced at diagnosis; and despite emerging treatment modalities, the overall prognosis for HCC remains poor ${ }^{3}$ (5-years survival $\sim 18 \%$ ), thus it needs to be prevented globally.

Risk factors contributing to the development of HCC are infections with $\mathrm{HBV}$ and $\mathrm{HCV}^{8-11}$, alcoholic cirrhosis, ${ }^{12}$ aflatoxin-contaminated food $^{13}$, non-alcoholic fatty liver disease (NAFLD) ${ }^{2,14}$, metabolic syndrome $^{15,16}$, smoking ${ }^{17}$, and possibly genetic components ${ }^{18,19}$. Except for the genetic components, these risk factors are modifiable through treatment and prevention interventions that should be initiated in childhood.

For over 15 years, we successfully conducted epidemiological research studies in Egypt ${ }^{20-27}$, where the burden of HCV infection is the highest worldwide and HCC incidence is on the rise ${ }^{1,4}$. We focused on investigating HCC risk factors and prevention, implementing the Egypt Smoking Prevention Research Initiative (ESPRI), and Project DARE (Drug Abuse Research in Egypt). Therefore, we are well-positioned to address this challenging disease risk factors and provide unique perspectives on how to reduce them. 


\section{Risk Factors and their Prevention}

\section{Hepatitis B}

Chronic infection with HBV is a well-established risk for HCC development. In HBV infected individuals, HCC risk increased with the increase in viral load ${ }^{8}$; and HCC incidence rate following HBV infection increased from 0.2 per 100 person-years in inactive carriers, to 0.6 in those with chronic HBV infection, to 3.7 in those with compensated cirrhosis ${ }^{28}$. Most of HCC cases in children and young adults are associated with HBV infection ${ }^{9,29}$.

HBV spread through contact with infected body fluids; thus the risk of infection is high among healthcare workers, intravenous drug users (IDU), and newborns of infected mothers. In addition, intra-familial transmission of HVB was reported among family members of chronic HBV carriers $^{30}$.

Since the development of an effective HBV vaccine and its widespread use, HCC incidence has substantially declined, particularly in HBV endemic areas ${ }^{31}$. Although newborn HBV vaccination has achieved tremendous progress toward elimination of perinatal and early childhood viral transmission ${ }^{32}$, HBV infection and HCC risk remain high in low-income countries with endemic HBV and where vertical transmission from mother to child is the main mode of infection; screening of all pregnant women and passive immunization with human hepatitis B immunoglobulin are not affordable ${ }^{33}$. Further, there are knowledge gaps among physicians and midwives about the use of HBV vaccine and immunoglobulin therapy to prevent HBV transmission from mother to newborn ${ }^{34}$. Interventions to fill these knowledge gaps among health care providers could, therefore, have a positive impact on lowering HBV transmission rates to children.

\section{Hepatitis C}

$\mathrm{HCV}$, like $\mathrm{HBV}$, is an established risk factor for HCC. It induces hepatic inflammation and ultimately cirrhosis and promotes hepatic cell transformation that leads to $\mathrm{HCC}^{10}$. Meta-analysis of 21 studies showed that individuals infected with HCV 1b genotype are at higher risk of developing HCC as compared to those infected with other HCV genotypes ${ }^{11}$. Parenteral anti-schistosomal therapy campaigns conducted from the 1950s through the 1980s, and using not well-sterilized needles, and the subsequent intra-familial HCV transmission from parent-to-offspring and sibling-to-sibling in rural communities ${ }^{35}$ resulted in Egypt having the largest burden of HCV infection in the world ${ }^{4}$, and a substantial rise in HCC incidence.

Unlike HBV, there is no HCV vaccine, and the burden of HCV continues to increase, because of the opiates epidemic among intra-venous drug users (IDU) in the U.S. and elsewhere. A meta-analysis of studies of chronic hepatitis
C patients showed a substantial reduction in HCC risk when anti-viral therapy achieved sustained viral response ${ }^{36}$. A Cochrane Database systemic review ${ }^{37}$ of interventions studies among IDUs found combination strategies, which included opiate substitution therapy and coverage of needle syringe program, substantially reduce the incidence of HCV.

Screening individuals at risk for HCV, and using the new direct-acting antiviral therapies have the potential to reduce HCV transmission and incidence, and its related morbidity. To screen for HCV, treat the active form, and/ or refer patients for counseling, education of healthcare providers is needed.

Considering that HCV transmission via IDU behaviors is a major factor sustaining the current HCV reservoir in the population and experimenting with drugs in childhood is associated with substance abuse and addiction later in life, prevention intervention should start among youth. Adverse childhood experiences were reported to impact subsequent behavior and substance abuse in adolescents and young adults ${ }^{38,39}$. and to be one of the most common contributing factors to substance use among Egyptian youth ${ }^{27}$. Training youth to acquire skills representing the 'executive function' ${ }^{40}$ and thus allowing them to deal with adversity and make healthy decisions ${ }^{41,42}$ was reported to be effective.

\section{Aflatoxin}

Dietary aflatoxin, produced by Aspergillus molds that infect stored grains and other foods, is classified by the International Agency of Research on Cancer (IARC) as a class 1 human carcinogen ${ }^{13}$. In Egypt where HCC is highly prevalent, studies have shown the presence of AFB1albumin adducts in human blood ${ }^{43,44}$, and that both local and imported food samples were positive for aflatoxin ${ }^{22}$.

A study from China reported HCC risk in patients with chronic HBV and aflatoxin exposure to be 60 times the risk in non-exposed ${ }^{45}$. Epidemiological studies, conducted in China, Taiwan and sub-Saharan Africa and addressing aflatoxin exposure and HCC risk, estimated the population attributable risk to be $17 \%$ overall, and higher among HBV positive $(21 \%)$ than in HBV negative $(8.8 \%)$ populations; aflatoxin appeared to interact multiplicatively with $\mathrm{HBV}$ to induce $\mathrm{HCC}^{46}$.

Aspergillus mold contamination and accumulation of aflatoxin in foods can be prevented through safe food storage and preparation practices. Awareness campaigns among populations exposed to aflatoxin were reported to reduce fungal contamination ${ }^{47}$. Studies in West Africa showed that aflatoxin metabolites were lowered after a low-cost, sustainable village intervention that emphasized proper storage of peanuts and hand picking and disposing of moldy nuts prior to cooking ${ }^{48}$. 
Although aflatoxin concentration in agricultural food and feed products is regulated worldwide, production of contaminated maize in Europe was, not only predicted because of climate change, but it was also observed in some countries ${ }^{49}$. Hence, regulations governing safe grain production and use must be reinforced, particularly in countries where other HCC risk factors are prevalent among children.

\section{Alcoholic cirrhosis}

In the US, from 1999 to 2016, annual cirrhosis-related mortality increased by $65 \%$ and that from HCC doubled ${ }^{50}$; driven entirely by alcohol, the highest cirrhosis-related mortality occurred in people aged 25-34 years ${ }^{50}$.

Alcohol use in chronic HCV infection doubles the risk for HCC as compared with the risk in HCV alone..$^{12}$ A study in Argentina reported alcoholic cirrhosis and HCV as the main contributing factors to $\mathrm{HCC}^{51}$. The odds of developing cirrhosis among chronic HCV patients were 2.3 higher in heavy alcohol drinkers as compared to nondrinkers or low quantity drinkers ${ }^{52}$. In a prospective study of 2215 patients with chronic viral hepatitis, in those with cirrhosis HCC risk was increased three times by heavy alcohol intake ${ }^{53}$. Therefore, prevention of alcohol abuse can significantly limit hepatic injury.

The National Institute on Alcohol Abuse and Alcoholism (NIAAA) developed a user-friendly, matrix-based tool (college alcohol intervention matrix or CollegeAIM) as a guide for school officials to inform decisions about alcohol intervention strategies and keep students safe ${ }^{54}$. According to a national survey, almost $60 \%$ of college students ages 18-22 drank alcohol in the past month ${ }^{55}$, and 2 out of 3 of them engaged in binge drinking during that same timeframe.

Preventing alcohol use initiation, like other addictive substance use, can greatly benefit from training youth to deal with adversity and make healthy decisions (see hepatitis C paragraph above) ${ }^{41,42}$. In addition, focusing on reducing early childhood adversity has been strongly recommended ${ }^{39,56}$, particularly for disadvantaged children and families. To date, children's healthcare providers have rarely addressed the social and emotional determinants of health and the context in which children live, despite the potential impacts of these factors on adult health.

\section{Non-alcoholic fatty liver diseases (NAFLD)}

NAFLD has been reported as a cause for $\mathrm{HCC}^{2,14}$. Considering the increase in the prevalence of NAFLD and nonalcoholic steatohepatitis, it is likely that these conditions will drive HCC incidence even higher than present levels if the obesity epidemic, the major underlying cause, continues unabated in many areas of the world ${ }^{57}$.
NAFLD, which is associated with metabolic syndrome, was more prevalent among HCC cases (37.1\%) compared to controls $(17.1 \%)$ and significantly associated with an elevated risk of HCC in a study using SEER-Medicare database ${ }^{15}$. A study of the Swedish cohort AMORIS showed thatelevated individual components of metabolic syndrome, i.e., triglycerides and elevated glucose, and diabetes were associated with an increased risk of developing HCC even without cirrhosis ${ }^{16}$. Type 2 diabetes was found to be independently associated with increased HCC risk in the Nurses' Health Study and the Health Professionals Followup Study; both of which are prospective cohorts of U.S. women $(n=120,826)$ and men $(n=50,284)$, respectively ${ }^{58}$. The risk increased with diabetes duration and with metabolic comorbidities, hence the suggestion that insulin resistance plays a role in HCC pathogenesis ${ }^{58}$.

Inherited factors have been associated with HCC risk in NAFLD. ${ }^{14}$ Some authors postulated that NAFLD results from the interaction between genetic predisposition and environmental, behavioral, and health factors, including diet, diabetes, and obesity ${ }^{18}$. Adiposity and BMI may act as risk modifiers of the putative genetic factor underlying fat accumulation in the liver ${ }^{19}$.

Considering that non-alcoholic steatohepatitis, the second leading cause of liver disease in adults awaiting liver transplantation in the $\mathrm{US}^{59}$, is a predisposing HCC risk factor, prevention intervention to reduce such risk is paramount. Improved diet, largely driven by increased consumption of fruits, vegetables, nuts, legumes, and decreased consumption of red meat and trans-fat, was associated with reduced risk of fatty liver and thus NAFLD ${ }^{60}$. The American Association for the Study of Liver Diseases recommends lifestyle modification, primarily a weight loss diet, for the treatment of NAFLD ${ }^{61}$. Interestingly, schoolbased obesity prevention intervention that included diet, education, and physical activity, can improve health among low-income schoolchildren ${ }^{62}$. After-school programs that integrates daily physical activity and health education among ethnic and socioeconomically diverse communities can be a significant resource for combating childhood obesity $^{63}$ and ultimately preventing diabetes, metabolic syndrome, and HCC.

\section{Other factors}

A systematic review of 81 cohort and case-control studies showed that cigarette smoking increases HCC incidence and mortality ${ }^{17}$. Therefore, smoking prevention strategies, particularly those intended to prevent children from taking up the habit, have the potential to further control HCC.

A review of 15 studies showed a possible association between specific pesticides and HCC risk ${ }^{64}$. VoPham et 
Table 1. Prevention Intervention Strategies, Recipients, and Modalities to Reduce Hepatocellular Carcinoma Risk Factors

\begin{tabular}{|c|c|c|c|}
\hline Strategy & Risk factor & Recipient & Modalities \\
\hline \multirow{2}{*}{ Vaccination } & \multirow{2}{*}{ HBV } & Newborn & Universal vaccination at birth \\
\hline & & Healthcare worker & Vaccination before employment; booster if no immunity in vaccinated individuals \\
\hline \multirow{4}{*}{ Screening } & \multirow{2}{*}{ HBV } & Healthcare worker & Verify if worker has HBV immunity from prior vaccination \\
\hline & & Pregnant mother & Verify if mother is chronically infected with HBV before delivery \\
\hline & $\mathrm{HCV}$ & Individuals at risk (IDU) & \\
\hline & Alcohol & Adolescents and adults & \\
\hline \multirow[t]{2}{*}{ Treatment } & HBV & $\begin{array}{l}\text { newborn to hepatitis } \\
\text { B chronically-infected } \\
\text { mother }\end{array}$ & IgG and HBV vaccine at birth \\
\hline & $\mathrm{HCV}$ & Infected Individuals & $\begin{array}{l}\text { New antiviral therapies; Opiate substitution therapy; Coverage of needle syringe } \\
\text { program }\end{array}$ \\
\hline \multirow{6}{*}{ Education } & HBV & Healthcare provider & Treat newborn to chronically-infected mothers with IgG and vaccinate \\
\hline & \multirow{3}{*}{$\mathrm{HCV}$} & Healthcare provider & Screen \& treat individuals as needed; refer to addiction specialist \\
\hline & & $\begin{array}{l}\text { Pediatric Healthcare } \\
\text { provider }\end{array}$ & $\begin{array}{l}\text { Address social and emotional determinants of health, particularly for children and } \\
\text { adolescents from disadvantaged communities }\end{array}$ \\
\hline & & School children & Train youth to acquire skills that will help them make healthy choices \\
\hline & HBV \& HCV & $\begin{array}{l}\text { Healthcare worker \& } \\
\text { affiliates }\end{array}$ & Train workers to apply universal precautions in handling body fluids and needles \\
\hline & $\begin{array}{l}\text { Aflatoxin \& } \\
\text { pesticides }\end{array}$ & Farming community & $\begin{array}{l}\text { Teach to read and understand labels \& best practices for aflatoxin safe grain produc- } \\
\text { tion, and for safely handling pesticides }\end{array}$ \\
\hline \multirow{7}{*}{$\begin{array}{l}\text { Education } \\
\text { including } \\
\text { for } \\
\text { Life Style } \\
\text { Change }\end{array}$} & \multirow{4}{*}{$\begin{array}{l}\text { Alcohol \& } \\
\text { Smoking }\end{array}$} & Healthcare provider & Screen, treat and refer for counseling \\
\hline & & $\begin{array}{l}\text { Pediatric healthcare } \\
\text { provider }\end{array}$ & $\begin{array}{l}\text { Address social and emotional determinants of health, particularly for children and } \\
\text { adolescents from disadvantaged communities }\end{array}$ \\
\hline & & College administrators & Address alcohol abuse on college campus \\
\hline & & School children & Train youth to acquire skills that will help them make healthy choices \\
\hline & \multirow{3}{*}{ NAFLD } & Healthcare provider & Address diet and exercise \\
\hline & & $\begin{array}{l}\text { Pediatric healthcare } \\
\text { provider }\end{array}$ & Address diet and exercise and social and emotional determinants of health \\
\hline & & School children & School physical education and after school activities \\
\hline
\end{tabular}

Abbreviations: HBV: hepatitis B virus; HCV: hepatitis C virus; NAFLD: non-alcoholic fatty liver diseases.

al. used GIS-based exposure estimates to study pesticide exposure and HCC in California and they found positive association with the organochlorine types ${ }^{64}$. Agricultural exposures to insecticides and herbicides are common in Egypt, and they were reported to increase the risk of $\mathrm{HCC}^{21}$, although not to the same level of magnitude as HBV and HCV. A study of farmers in Egypt, of whom $61 \%$ did not receive school education, revealed that the more educated the individuals were the more knowledge they have about pesticides and their safe use ${ }^{65}$. Another educational intervention to improve farming families' knowledge and practices in protecting their children from exposure to pesticides showed that one month after the intervention, knowledge and practice performance were better, not only among younger and more educated participants, but also among those assigned to the videotape compared to those assigned to the lecture ${ }^{66}$. Therefore, basic education leading to the ability to read and understand the safe handling of pesticides is necessary for avoiding contamination and exposure, not only among farmers, but also among their children.

\section{Conclusion}

As shown in Table 1, prevention interventions, through vaccination against infectious hepatitis and early avoidance of established risk factors, such as fatty liver, alcoholism, and substance use, would be highly effective ways to curb HCC incidence. A focus on reducing early childhood adversity and training young children to make healthy decisions to avoid alcoholism, smoking, and intravenous drugs, and thus potential HCV infection, has been strongly recommended; this is another prevention strategy in childhood to help reduce HCC incidence later in life.

\section{References}

1. Bray F, Ferlay J, Soerjomataram I, et al. Global cancer statistics 2018: GLOBOCAN estimates of incidence and mortality worldwide for 36 cancers in 185 countries. CA Cancer J Clin. 2018; 0: 1-31.

2. Petrick JL, Yang B, Altekruse SF, et al. Risk factors for intrahepatic and extrahepatic cholangiocarcinoma in the United States: A populationbased study in SEER-Medicare, PLOS ONE. 2017; 12: e0186643.

3. Noone AM, Howlader N, Krapcho M, et al. SEER Cancer Statistics Review, 1975-2015, National Cancer Institute. Bethesda, MD, https:// seer.cancer.gov/csr/1975_2015/, based on November 2017 SEER data submission, posted to the SEER web site, April 2018. 
4. Centers for Disease Control and Prevention (CDC). Progress toward prevention and control of hepatitis C virus infection--Egypt, 20012012. MMWR. 2012; 61: 545-549.

5. Chen CJ, Wang LY, Yu MW. Epidemiology of hepatitis B virus infection in the Asia-Pacific region. J Gastroenterol Hepatol. 2000; 15: Suppl:E3-6.

6. Dhir M, Melin AA, Douaiher J, et al. A Review and Update of Treatment Options and Controversies in the Management of Hepatocellular Carcinoma. Ann Surg. 2016; 263: 1112-1125.

7. Heimbach JK, Kulik LM, Finn RS, et al. AASLD guidelines for the treatment of hepatocellular carcinoma. Hepatology. 2018; 67: 358380 .

8. Chen CJ, Yang HI, Su J, et al. REVEAL-HBV Study Group. Risk of hepatocellular carcinoma across a biological gradient of serum hepatitis B virus DNA level. JAMA. 2006; 295: 65-73.

9. Wu TC, Tong MJ, Hwang B, et al. Primary hepatocellular carcinoma and hepatitis B infection during childhood. Hepatology. 1987; 7: 46-48.

10. Lemon SM, McGivern DR. Is hepatitis C virus carcinogenic? Gastroenterology. 2012 May; 142(6): 1274-8.

11. Raimondi S, Bruno S, Mondelli MU, et al. virus genotype $1 \mathrm{~b}$ as a risk factor for hepatocellular carcinoma development: a meta-analysis. Hepatol. 2009; 50: 1142-1154.

12. Morgan TR, Mandayam S, Jamal MM. Alcohol and hepatocellular carcinoma. Gastroenterology. 2004; 127: S87-96.

13. International Agency for Research on Cancer. Some Traditional Herbal Medicines, Some Mycotoxins, Napht halene and Styrene. IARC Monographs on the Evaluation of Carcinogenic Risks to Humans. Vol 82. Lyon, France: IARC Press; 2002.

14. Dongiovanni P, Romeo S, Valenti L. Hepatocellular carcinoma in nonalcoholic fatty liver: role of environmental and genetic factors. World J Gastroenterol. 2014; 20: 12945-12955.

15. Welzel TM, Graubard BI, Zeuzem S, et al. Metabolic syndrome increases the risk of primary liver cancer in the United States: A study in the SEER-medicare database. Hepatology. 2011; 54: 463-471.

16. Nderitu P, Bosco C, Garmo H, et al. The association between individual metabolic syndrome components, primary liver cancer and cirrhosis: A study in the Swedish AMORIS cohort, Int J Cancer. 2017; 141: 11481160.

17. Abdel-Rahman 0, Helbling D, Schöb 0, et al. Cigarette smoking as a risk factor for the development of and mortality from hepatocellular carcinoma: An updated systematic review of 81 epidemiological studies. J Evid Based Med. 2017; 10: 245-254.

18. Anstee QM, Seth D, Day CP. Genetic factors that affect risk of alcoholic and nonalcoholic fatty liver disease. Gastroenterology. 2016; 150: 1728-1744.

19. Stender S, Kozlitina J, Nordestgaard BG, et al. Adiposity amplifies the genetic risk of fatty liver disease conferred by multiple loci. Nat Genet. 2017; 49: 842-847.

20. Abdel-Hamid M, El-Daly M, Molnegren V, et al. Genetic diversity in hepatitis $C$ virus in Egypt and possible association with hepatocellular carcinoma. J Gen Virol. 2007; 88: 1526-1531.

21. Ezzat S, Abdel-Hamid M, Eissa SA, et al. Associations of pesticides, HCV, HBV, and hepatocellular carcinoma in Egypt. Int J Hyg Environ Health. 2005; 208: 329-339.

22. Anwar WA, Khaled HM, Amra HA, et al. Changing pattern of hepatocellular carcinoma (HCC) and its risk factors in Egypt: possibilities for prevention. Mutat Res. 2008; 659: 176-184.

23. Mohlman MK, Boulos DN, El Setouhy M, et al. A Randomized, Controlled Community-Wide Intervention to Reduce Environmental Tobacco Smoke Exposure. Nicotine Tob Res. 2013; 15: 1372-1381.
24. Amr S, Iarocci EA, Nasr GR, et al. Multiple Pregnancies, Hepatitis C, and Risk for Hepatocellular Carcinoma in Egyptian Women. BMC Cancer. 2014; 4: 893

25. Saleh DA, Amr S, Jillson IA, et al. Preventing Hepatocellular Carcinoma in Egypt: Results of a Pilot Health Education Intervention Study. BMC Res Notes. 2015; 8: 384.

26. Mohlman MK, Saleh D, Ezzat S, et al. Viral Transmission Risk Factors in an Egyptian Population with High Hepatitis C Prevalence. BMC Public Health. 2015; 15: 1030 .

27. Loffredo CA, Boulos DNK, Saleh DA, et al. Substance Use by Egyptian Youth: Current Patterns and Potential Avenues for Prevention, Substance Use \& Misuse. 2015; 50: 609-618.

28. Fattovich G, Bortolotti F, Donato F. Natural history of chronic hepatitis B: special emphasis on disease progression and prognostic factors. J Hepatol. 2008; 48: 335-352.

29. Chang MH, Chen DS, Hsu HC, et al. Maternal transmission of hepatitis B virus in childhood hepatocellular carcinoma. Cancer. 1989; 64: 2377-2380.

30. Sofian M, Banifazl M, Ziai M, et al. Intra-familial Transmission of Hepatitis B Virus Infection in Arak, Central Iran. Iranian J Pathol. 2016; $11: 328-333$

31. Chang MH, You SL, Chen CJ, et al. Decreased incidence of hepatocellular carcinoma in hepatitis B vaccinees: a 20-year follow-up study. J Nat Cancer Inst. 2009; 101: 1348-1355.

32. Ropero-Álvarez AM, Pérez-Vilar S, Pacis-Tirso C, et al. Progress in vaccination towards hepatitis $B$ control and elimination in the Region of the Americas. BMC Public Health. 2017; 17: 325.

33. Franco E, Bagnato B, Marino MG, et al. Epidemiology and prevention in developing countries. World J Hepatol. 2012; 4: 74-80.

34. Adjei CA, Asamoah R, Atibila F, et al. Mother-to-child transmission of hepatitis B: extent of knowledge of physicians and midwives in Eastern region of Ghana. BMC Public Health. 2016; 16: 537.

35. Saleh DA, Shebl FM, El-Kamary SS, et al. Incidence and risk factors for community-acquired hepatitis $C$ infection from birth to 5 years of age in rural Egyptian children. Trans R Soc Trop Med Hyg. 2010; 104: 357-363.

36. Singal AK, Singh A, Jaganmohan S, et al. Antiviral therapy reduces risk of hepatocellular carcinoma in patients with hepatitis $C$ virus-related cirrhosis. Clin Gastroenterol Hepatol. 2010; 8:192-199.

37. Platt L, Minozzi S, Reed J, et al. Needle syringe programmes and opioid substitution therapy for preventing hepatitis $\mathrm{C}$ transmission in people who inject drugs. Cochrane Database Syst Rev. 2017; 9: CD012021.

38. CDC. Centers for Disease Control and Prevention. Adverse childhood experiences. Available at: www.cdc.gov/violenceprevention/ acestudy. Accessed June 30, 2018.

39. Hertzman C. The significance of early childhood adversity. Paediatr Child Health. 2013; 18: 127-128.

40. Riggs NR, Pentz MA. Inhibitory control and the onset of combustible cigarette, e-cigarette, and hookah use in early adolescence: the moderating role of socioeconomic status. Child Neuropsychology. 2016; 22(6): 1-13.

41. Gewin AM, Hoffman B. Introducing the cultural variables in schoolbased substance abuse prevention. Drugs: Education, Prevention and Policy. 2016; 23(1): 1-14

42. Pentz MA, Riggs NR, Warren CM. Improving substance use prevention efforts with executive function training. Drug \& Alcohol Dependence. 2016; 163(Suppl 1): S54-S59.

43. Turner PC, Loffredo C, Kafrawy SE, et al. Pilot survey of aflatoxinalbumin adducts in sera from Egypt. Food Addit Contam Part A. 2008; 25: 583-587. 
44. Polychronaki N, Wild CP, Mykkanen $\mathrm{H}$, et al. Urinary biomarkers of aflatoxin exposure in young children from Egypt and Guinea. Food Chem Toxicol. 2008; 46: 519-526.

45. Qian GS, Ross RK, Yu MC, et al. A follow-up study of urinary markers of aflatoxin exposure and liver cancer risk in Shanghai, People's Republic of China. Cancer Epidemiol Biomarkers Prev. 1994; 3: 3-10.

46. Liu Y, Chang CC, Marsh GM, et al. Population attributable risk of aflatoxin-related liver cancer: systematic review and meta-analysis. Eur J Cancer. 2012; 48: 2125-2136.

47. James B, Adda C, Cardwell K, et al. Public information campaign on aflatoxin contamination of maize grains in market stores in Benin, Ghana and Togo. Food Addit Contam. 2007; 24: 1283-1291.

48. Turner PC, Sylla A, Gong YY, et al. Reduction in exposure to carcinogenic aflatoxins by postharvest intervention measures in west Africa: a community-based intervention study. Lancet. 2005; 365:1950-1956.

49. Battilani P, Toscano P, Van der Fels-Klerx HJ, et al. Aflatoxin B1 contamination in maize in Europe increases due to climate change. Sci Rep. 2016 Apr 12; 6: 24328. doi: 10.1038/srep24328.

50. Tapper EB, Parikh ND. Mortality due to cirrhosis and liver cancer in the United States, 1999-2016: observational study. BMJ. 2018; 362 : k2817.

51. Fassio E, Míguez C, Soria S, et al. Etiology of hepatocellular carcinoma in Argentina: results of a multicenter retrospective study. Acta Gastroenterol Latinoam. 2009; 39: 47-52.

52. Hutchinson SJ, Bird SM, Goldberg DJ. Influence of alcohol on the progression of hepatitis $\mathrm{C}$ virus infection: a meta-analysis. Clin Gastroenterol Hepatol. 2005; 3: 1150-1159.

53. Ikeda K, Saitoh S, Suzuki Y, et al. Disease progression and hepatocellular carcinogenesis in patients with chronic viral hepatitis: a prospective observation of 2215 patients. J Hepatol. 1998; 28: 930-938.

54. About the Interventions in CollegeAIM. https://www. collegedrinkingprevention.gov/CollegeAIM/Introduction/ AboutInterventions.aspx Accessed September 20, 2018

55. Substance Abuse and Mental Health Services Administration (SAMHSA). 2015 National Survey on Drug Use and Health (NSDUH). Table 6.84B-Tobacco Product and Alcohol Use in Past Month among Persons Aged 18 to 22, by College Enrollment Status: Percentages, 2014 and 2015. Available at: https://www.samhsa.gov/data/sites/ default/files/NSDUH-DetTabs-2015/NSDUH-DetTabs-2015/NSDUHDetTabs-2015.htm\#tab6-84b
56. Bethell CD, Solloway MR, Guinosso S, et al. Prioritizing Possibilities for Child and Family Health: An Agenda to Address Adverse Childhood Experiences and Foster the Social and Emotional Roots of Well-being in Pediatrics. Acad Pediatr. 2017; 17(7S): S36-S50.

57. Massoud O, Charlton M. Nonalcoholic Fatty Liver Disease/ Nonalcoholic Steatohepatitis and Hepatocellular Carcinoma, Clinics in Liver Disease. 2018; 22: 201-211.

58. Simon TG, King LY, Chong DQ, et al. Diabetes, metabolic comorbidities, and risk of hepatocellular carcinoma: Results from two prospective cohort studies Hepatology. 2018 May; 67(5): 1797-1806. doi: 10.1002/hep.29660. Epub 2018 Mar 26.

59. Wong RJ, Aguilar M, Cheung R, et al. Nonalcoholic steatohepatitis is the second leading etiology of liver disease among adults awaiting liver transplantation in the United States. Gastroenterology. 2015; 148: 547-555.

60. Ma J, Hennein R, Liu C, et al. Improved Diet Quality Associates With Reduction in Liver Fat, Particularly in Individuals With High Genetic Risk Scores for Nonalcoholic Fatty Liver Disease. Gastroenterology. 2018; 155: 107-117.

61. Chalasani N, Younossi Z, Lavine JE, et al. The diagnosis and management of nonalcoholic fatty liver disease: practice guidance from the American Association for the Study of Liver Diseases. Hepatology. 2018; 67: 328-357.

62. Hollar D, Messiah SE, Lopez-Mitnik G, et al. Effect of a Two-Year Obesity Prevention Intervention on Percentile Changes in Body Mass Index and Academic Performance in Low-Income Elementary School Children. Am J Public Health. 2010; 100: 646-653.

63. Messiah SE, Diego A, Kardys J, et al. Effect of a park-based after-school program on participant obesity-related health outcomes. Am J Health Promot. 2015; 29: 217-225.

64. VoPham T, Bertrand KA, Hart JE, et al. Pesticide exposure and liver cancer: a review. Cancer Causes Control. 2017 Mar; 28(3): 177-190.

65. Gaber S, Abdel-Latif SH. Effect of education and health locus of control on safe use of pesticides: a cross sectional random study. J Occup Med Toxicol. 2012; 7: 3 .

66. Farahat TM, Farahat FM, Michael AA. Evaluation of an educational intervention for farming families to protect their children from pesticide exposure. East Mediterr Health J. 2009; 15: 47-56. 